
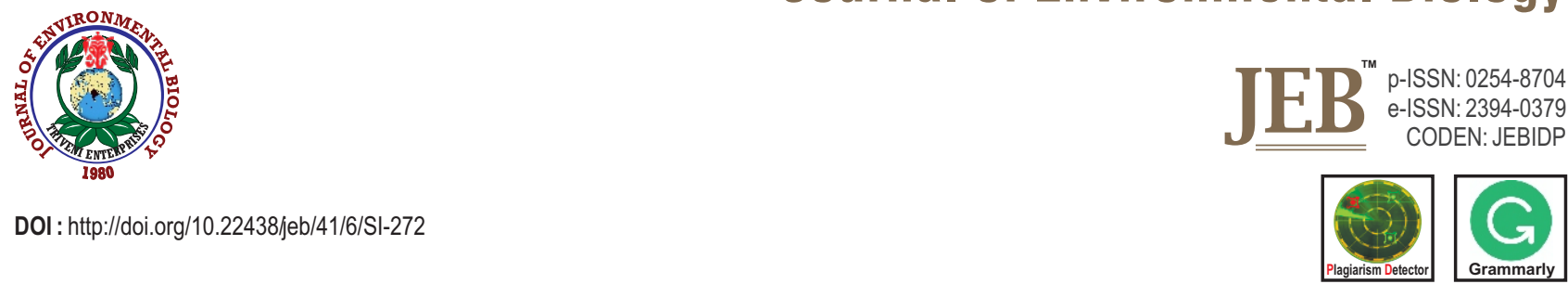

\title{
Systematic trait based identification and characterization of Indian wheat varieties released during different time scales
}

\author{
S. Sharma', S. Yashveer', V. Singh ${ }^{3}$, R.C. Punia', Hemender', S. Sangwan'² V.S. Mor' and M. Khan ${ }^{4}$ \\ ${ }^{1}$ Department of Seed Science and Technology, CCS Haryana Agricultural University, Hisar-125 004, India \\ ${ }^{2}$ Department of Molecular Biology, Biotechnology and Bioinformatics, CCS Haryana Agricultural University, Hisar- 125004 , India \\ ${ }^{3}$ RDS Seed Farm, CCS Haryana Agricultural University, Hisar-125 004, India \\ ${ }^{4}$ Agricultural Research Station (SKN Agriculture University, Jobner), Fatehpur-Shekhawati-332 301, India \\ *Corresponding Author Email : mkhanstat@gmail.com
}

\section{Abstract}

Aim: Wheat varieties have been developed for yield improvement by modern plant breeding methods from the basic pedigree for long which brought about a restricted hereditary base. Therefore, the present study was designed to develop identification keys and characterize different wheat varieties on the basis of multiple traits.

Methodology: Thirty-four Indian wheat (Triticum spp.) varieties released during different time scales were assessed for diversity through various approaches based on morphological, seed vigour, biochemical and molecular characterization.

Results: The results revealed that a considerable amount of variation was present in phenotypic characters such as flag leaf, plant height, spike and yield related characters. Seed vigour parameters included test weight, seedling dry weight, seedling length, accelerated ageing test and vigour indices showed significant variability among varieties. Dehydrogenase activity, tetrazolium test and electrical conductivity of seed leachates were also found worth studying for diversity. Molecular characterization included twenty-one SSRs selected after screening of 45 , amplified 46 alleles, among them 42 alleles were polymorphic. PIC value varied from 0.1 to 0.65 and similarity coefficient extended from 0.34 to 0.87 .

Interpretation: Genetic diversity pattern analysis of genotypes based on their geographical origin did not show any clear relation, however characters like plant height, seed boldness and seedling vigour indices of varieties showed a trend with a chronology of their release. Different perspectives used in the study successfully categorized wheat genotypes into various groups.

Key words: Chronology, Genetic diversity, Morphological traits, Seed vigour traits, SSRs
34 Wheat genotypes released during different time scales ( 30 bread wheat +4 durum genotypes)

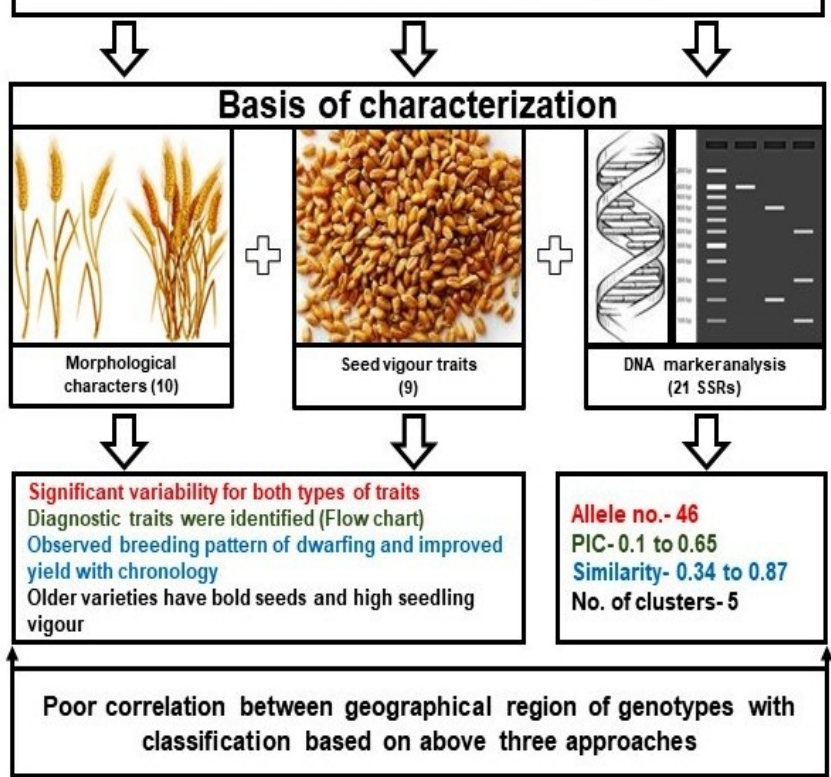

How to cite : Sharma, S., S. Yashveer, V. Singh, R.C. Punia, Hemender, S. Sangwan, V.S. Mor and M. Khan: Systematic trait based identification and characterization of Indian wheat varieties released during different time scales. J. Environ. Biol., 41, 1748-1760 (2020). 


\section{Introduction}

India has witnessed splendid advances in food crops production and productivity in mid-sixties, and dwarf wheat owes the credit for bringing this self-sufficiency to it out of hopeless and deplorable conditions. The diverse growing environments of India support the production of all types of wheat i.e., bread wheat (Triticum aestivum), durum (T. durum), few fields of Khapli or $T$. Dicoccum and T. monococcum. This huge genetic diversity in wheat is worthless until and unless if it is characterized, assessed and documented correctly for its use in enhancing crop improvement. Proper characterization and cataloguing of the material within reach is of prime significance to utilize the available germplasm (Singh et al., 2016).

The domestication process, which selected only a limited species has led to reduced genetic diversity of plants under cultivation (Tanksley and McCouch, 1997) as selection and spreading of only specific genes were done which guide agronomically important traits. This process has directed the cultivated plant species away from their wild relatives (Clark et al., 2004). Variety is the fundamental input and cultivation of each variety depends on its related profit or loss. Based on the local preferences and agro-climatic conditions, a number of varieties have been cultivated commercially. Varieties of wheat have been developed for yield improvement by breeding among the common pedigree for long, and eventually, have resulted in a narrow genetic base. A situation of genetic vulnerability to different biotic and abiotic stresses has been created by this narrowing (Kumar et al., 2013).

Identification of species and difference in varieties have long been carried out from the times of Mendel till mid-eighties purely with morphological characters (Mollasadeghi et al., 2013). However, in the present era, besides morphological descriptors biochemical and molecular markers have also proved effective tools for identification and characterization. Most of the breeding programmes give subordinate importance to seed related traits. But, these seed traits are the determining factors for germination rate, uniformity, growth, abiotic stress tolerance after sowing and performance retention after storage, which is crucial for seed supply chain and easy availability of quality seed to the farmers.

Wheat breeding has now stepped up and become more efficient with the use of molecular markers. Wheat germplasm characterization is best suited with molecular markers as detection based on them is independent of field environment and environment influenced traits (Sud et al., 2005; Grewal et al., 2007; Salem et al., 2008). The short tandem repetitive DNA sequences (microsatellites), more specifically the simple sequence repeats (SSRs) are utilized for genotypic diversity assessment as they are often cultivar specific. SSRs are codominant by nature and are highly polymorphic and thus, are extensively used in genetic linkage mapping, diversity assessment and marker assisted selection (Li et al., 2014).

In the present study, an aggregate methodology of morphological characters, seed related attributes and molecular markers has been used to recognize diagnostic characters of different wheat varieties and to build up genetic relations among superior genotypes which could be harnessed in future wheat improvement program.

\section{Materials and Methods}

Plant material : Seeds of thirty-four widely grown wheat (Triticum spp.) varieties (Table 1) of Indian origin were obtained from Wheat and Barley Section, Department of Genetics and Plant Breeding, CCS Haryana Agricultural University, Hisar. The field experiment was laid in a Randomized Block Design layout with three replications in the experimental area of Department of Seed Science and Technology, CCS Haryana Agricultural University, Hisar, geographically located at $29^{\circ} 09^{\prime} \mathrm{N} 75^{\circ} 42^{\prime} \mathrm{E}$. Data were recorded by randomly selecting five plants from each replication for various morphological characters such as plant height, tillers per plant, flag leaf length, peduncle length, spike length, spikelets per spike, spikelet weight, awn length, grains per spike and yield perplant.

Seed vigour parameters included test weight, seedling length, seedling dry weight, vigour indices, stress test (accelerated ageing). Biochemical tests for seed vigour assessment included tetrazolium test, electrical conductivity test and dehydrogenase activity test. Seed vigour parameters were studied in growth chambers using Complete Randomised Design (CRD) with three replications. Genetic diversity was assessed using SSRs. Forty-five SSRs were used in this study. Out of these, twenty-one primers were amplified (Table 2).

Seedling length and dry weight : Fifty seeds of each genotype were planted between sufficiently moistened blotter paper and kept in the germinator at $20^{\circ} \mathrm{C}$ and $90 \pm 1 \%$ R.H. After seven days, ten seedlings from each treatment were randomly selected and their length (root+shoot) was recorded. The length of ten seedlings was then averaged to calculate mean seedling length and expressed in centimetres (ISTA, 1999). Seedlings whose length was recorded were then dried in oven at $80 \pm 1^{\circ} \mathrm{C}$ and their dry weight was recorded using digital balance. Average of ten seedlings was calculated and expressed in milligrams (ISTA, 1999).

Vigour indices : Seedling vigour indices were calculated by following the formulae (Abdul-Baki and Anderson, 1973).

Vigour Index-I = Standard germination(\%)×Average seedling length $(\mathrm{cm})$

Vigour Index-II = Standard germination (\%) $\times$ Average seedling dry weight (g) 
Table 1: Details of wheat varieties used in the study

\begin{tabular}{|c|c|c|c|}
\hline Name of Variety/Genotype & Year of release & Pedigree & Origin \\
\hline \multicolumn{4}{|c|}{ Triticum aestivum } \\
\hline C518 & 1933 & TYPE 8A/TYPE 9 & CCSHAU, Hisar \\
\hline C 306 & 1965 & RGN/CSK 3//2“C 591/3/C 217/N 14//C281 & CCSHAU, Hisar \\
\hline Kharchia 65 & 1966 & Kharchia Local/EG 953 & Kharchia, Pali (Raj.) \\
\hline Sonalika & 1967 & II54-388/AN/3/YT54/N10B/LR64 & PAU, Ludhiana \\
\hline WH 147 & 1977 & $\mathrm{E} 4870 / \mathrm{C} 286 / \mathrm{C} 273 / 4 / \mathrm{S} 339 / \mathrm{PV} 18$ & CCSHAU, Hisar \\
\hline HUW 234 & 1984 & HUW 12* 2/ CPAN 1666//HUW 12 & BHU, Varanasi \\
\hline HD 2285 (Gobind) & 1985 & 249/HD2150//HD 2186 & IARI, New Delhi \\
\hline Kundan (DL153-2) & 1985 & TANORI 71/NP 890 & IARI, New Delhi \\
\hline WH 283 & 1985 & HD1981/RAJ821 & CCSHAU, Hisar \\
\hline PBW 175 & 1989 & HD 2160/WG 1025 & PAU, Ludhiana \\
\hline WH 157 & 1990 & NP876/S308//CNO/8156 & CCSHAU, Hisar \\
\hline WH542 & 1992 & JUP/BJY"S"//URES & CCSHAU, Hisar \\
\hline Kanchan (DL 803-3) & 1994 & HUW 202/K 7537/MUTANT OF HD2160 & IARI, New Delhi \\
\hline RAJ 3765 & 1996 & HD 2402/VL 639 & RAU, Bikaner \\
\hline PBW373 & 1997 & ND/VG9144//KAL/BB/3/YCO"S/4/VEE\#5 "S & PAU, Ludhiana \\
\hline HD 2733 (VSM) & 1997 & ATTILA/3/TUI/CARC//CHEN/CHTO/4/ATTILA & IARI, New Delhi \\
\hline NW 1014 & 1998 & HAHN 'S' & NDKVV, Faizabad \\
\hline Sonak & 1998 & II54.388/AN/3/YT54/N10B/LR & CCSHAU, Hisar \\
\hline UP 2425 & 1999 & HD 2320/UP2263 & GBPUAT, Pantnagar \\
\hline KRL 19 & 2002 & PBW 255/KRL 1-4 & CSSRI, Karnal \\
\hline MR1 & 2002 & NA & RAU, Bikaner \\
\hline DBW 14 & 2003 & RAJ3765/PBW 343 & DWR, Karnal \\
\hline DBW 16 & 2006 & RAJ 3765/WR 484//HUW 468 & DWR, Karnal \\
\hline DBW 17 & 2006 & CMH79A.95/3*CNO 79//RAJ3777 & DWR, Karnal \\
\hline WH 1025 & 2009 & C591/PBW 231 & CCSHAU, Hisar \\
\hline HD 2967 & 2011 & ALD/COC//URES/HD2160M/HD2278 & IARI, New Delhi \\
\hline WH1105 & 2013 & MILAN/S87230//BABAX & CCSHAU, Hisar \\
\hline WH1124 & 2014 & MUNIA/CHTO//AMSEL & CCSHAU, Hisar \\
\hline \multicolumn{4}{|c|}{ Advance lines/genotypes } \\
\hline WH1129 & - & CS/TH.CS//3*PVN/3/MIRLO/BUC/4/MILAN/5/TILHI & CCSHAU, Hisar \\
\hline WH 1138 & - & PBW 65*2/PASTOR & CCSHAU, Hisar \\
\hline \multicolumn{4}{|c|}{ Triticum durum } \\
\hline WH 896 & 1995 & STIL"S"/YAV"S //PEN"S & CCSHAU, Hisar \\
\hline WH 912 & 2002 & HUI 'S'/YAV 'S'//FULI 'S'/ALYAR 84 & CCSHAU, Hisar \\
\hline WHD 943 & 2011 & GLARE/PLATA-16//AJAIA-3/SILVER 16 & CCSHAU, Hisar \\
\hline WHD 948 & 2014 & ALTAR 84/STINT//SILVER & CCSHAU, Hisar \\
\hline
\end{tabular}

Accelerated ageing test : Sufficient number of seeds were placed in a single layer on the wire mesh trays fitted in plastic boxes having $40 \mathrm{ml}$ of distilled water and placed in ageing chamber. The seeds aged at $40 \pm 1^{\circ} \mathrm{C}$ and $100 \% \mathrm{RH}$ for $72 \mathrm{hr}$ were tested for germination in three replicates of 100 seeds for every genotype. The number of normal seedlings were counted on $7^{\text {th }}$ day and indicated in percentage (AOSA, 1983).

Electrical conductivity of seed leachates : Fifty normal undamaged randomly selected seeds for each genotype were soaked in $75 \mathrm{ml}$ distilled water and kept at $25^{\circ} \mathrm{C}$ for $24 \mathrm{hr}$. The EC of leachates was estimated with EC meter and conductivity was indicated in $\mathrm{S} \mathrm{cm}^{-1}$ seed $^{-1}$ (ISTA, 1999).
Dehydrogenase activity: One-gram seed of each genotype in three replicates was ground to go through a 20 mesh screen. 200 mg flour was soaked in $5 \mathrm{ml}$ tetrazolium solution $(0.5 \%)$ at $38^{\circ} \mathrm{C}$ for $3 \mathrm{hr}$ followed by centrifugation at $10000 \mathrm{rpm}$ for $3 \mathrm{~min}$. Supernatant was poured off and formazan was extracted with 10 $\mathrm{ml}$ acetone for $16 \mathrm{~h}$ followed by centrifugation. Absorbance of the solution was recorded by Systonic Spectrophotometer 169 at 480 $\mathrm{nm}$ and indicated as change in O D/g/ml (Kittock and Law, 1968).

Tetrazolium test : Fifty seeds in three replicates were soaked in $50 \mathrm{ml}$ water for $16 \mathrm{hr}$ at $25^{\circ} \mathrm{C}$ to activate dehydrogenase enzyme. Seeds were sliced longitudinally along the groove (for exposing the embryo) and stained in $0.5 \%$ tetrazolium solution $(2,3,5-$ 
Table 2 : Amplification details of 21 SSR primers

\begin{tabular}{lllll}
\hline SSR locus & Amp. Range (bp) & Allele No. & PIC & Amplification Pattern \\
\hline Xgwm 3 & $120-180$ & 2 & 0.32 & Polymorphic \\
Xgwm 11 & $200-220$ & 2 & 0.32 & Polymorphic \\
Xgwm 16 & $180-250$ & 2 & 0.28 & Polymorphic \\
Xgwm 33 & $120-200$ & 2 & 0.10 & Polymorphic \\
Xgwm 46 & $160-200$ & 3 & 0.65 & Polymorphic \\
Xgwm68 & $120-200$ & 2 & 0.35 & Polymorphic \\
Xgwm 102 & 150 & 1 & 0 & Monomorphic \\
Xgwm 111 & $140-280$ & 4 & 0.47 & Polymorphic \\
Xgwm112 & $80-120$ & 3 & 0.54 & Polymorphic \\
Xgwm136 & $280-1000$ & 3 & 0.29 & Polymorphic \\
Xgwm146 & $180-220$ & 3 & 0.60 & Polymorphic \\
Xgwm157 & 100 & 1 & 0 & Monomorphic \\
Xgwm165 & 2 & 0.28 & Polymorphic \\
Xgwm186 & $200-250$ & 2 & 0.47 & Polymorphic \\
Xgwm261 & $100-120$ & 2 & 0.48 & Polymorphic \\
Xgwm311 & $180-200$ & 2 & 0.31 & Polymorphic \\
Xgwm359 & $120-130$ & 1 & 0 & Monomorphic \\
Xgwm400 & 220 & 2 & Polymorphic \\
Xgwm537 & $150-250$ & 3 & 0.20 & Polymorphic \\
Xgwm573 & $220-250$ & 2 & 0.54 & Monomorphic \\
Xgwm601 & $200-210$ & 2 & 0 & Polymorphic \\
\hline
\end{tabular}

triphenyl tetrazolium chloride) for $1 \mathrm{hr}$ at $38^{\circ} \mathrm{C}$, seeds rinsed briefly in water and examined under magnification (Moore, 1973). Seeds stained completely red were considered as viable and indicated in percentage.

DNA extraction, PCR amplification and amplified product detection : Leaves from two-week-old plants were collected and pooled for genomic DNA extraction. CTAB (cetyltrimethyl ammonium bromide) method (Saghai-Maroof et al., 1984) was followed for genomic DNA extraction and agarose gel electrophoresis was performed to check the concentration and integrity of extracted DNA. DNA was diluted to $100 \mathrm{ng} \mathrm{\mu l}^{-1}$ for PCR amplification reaction. PCR reaction volume of $20 \mu \mathrm{l}$ included $1 \mu \mathrm{l}$ template DNA, $2.0 \mu \mathrm{l}$ 10X PCR buffer, $0.5 \mu \mathrm{l} 10 \mathrm{mM}$ dNTP mix, 0.4 $\mu \mathrm{l} 2.5 \mu \mathrm{M}$ of each downstream and upstream primers, $0.3 \mu \mathrm{l} 5 \mathrm{U}$ $\mu \mathrm{I}^{-1}$ Taq DNA Polymerase and $15.4 \mu \mathrm{l}$ sterile distilled water. PCR amplification was carried out using BIORAD S 1000 thermocycler. PCR protocol covered the steps of initial denaturation at $94^{\circ} \mathrm{C}$ for $4 \mathrm{~min}$ followed by 39 cycles of denaturation at $94^{\circ} \mathrm{C}$ for $1-2 \mathrm{~min}$, annealing at $50-60^{\circ} \mathrm{C}$ depending on the primers for $1 \mathrm{~min}$, elongation at $72^{\circ} \mathrm{C}$ for $1 \mathrm{~min}$ and final extension for $10 \mathrm{~min}$ at $72^{\circ} \mathrm{C}$. Products were stored at $4^{\circ} \mathrm{C}$ untill further use. $2 \%$ AGE was used to detect the amplified products at $4 \mathrm{~V} / \mathrm{cm}$ in $0.5 \mathrm{XTBE}$ buffer.

Molecular data analysis : Alleles were scored in the form of 0/1 matrix, 0 (absence) or 1 (presence) to ascertain genetic similarity distance using 'SIMQUAL' sub-programme of NTSYS-PC (version 2.02) software (Rohlf, 2000). SAHN sub-programme of NTSYS-PC constructed the dendrogram by using genetic distance matrix based on Unweighted Pair-Group Method with Arithmetic Average (UPGMA) method. Molecular weights (in base pairs) of amplified products were assessed and descriptive statistics including the number of alleles per locus, major allele frequency and Polymorphism Information Content (PIC) values were worked out (Anderson et al., 1993).

\section{Results and Discussion}

The present study undertakes consolidated investigation of data on the basis of phenotypic attributes and molecular markers. Here, the grouping of genotypes for a particular trait was done followed by further sub division with reference to the next trait and so on. In this order, some genotypes showed their distinctivity from other genotypes for a particular trait during systematic classification in the flow chart (Fig. 1, 2). Therefore, the sequence of traits generated with genotypes falling into specific categories can help in identification of a specific genotype. This type of trait based identification key development was also done by Kumar et al. (2013) in guar, Singh et al. (2016) in bajra and Chauhan et al. (2020) in wheat for respective set of genotypes in their studies. Here, in the present study, we followed the approach of quantification of different traits in high, medium and low categories. Wasim et al. (2020) also adopted similar approach and categorised popular Indian wheat varieties and advance lines on the basis of morphological characters and provided quantification categories for different characters.

Plant height is a relative genotypic character and is affected by environmental variations. Some varieties could be tall, 


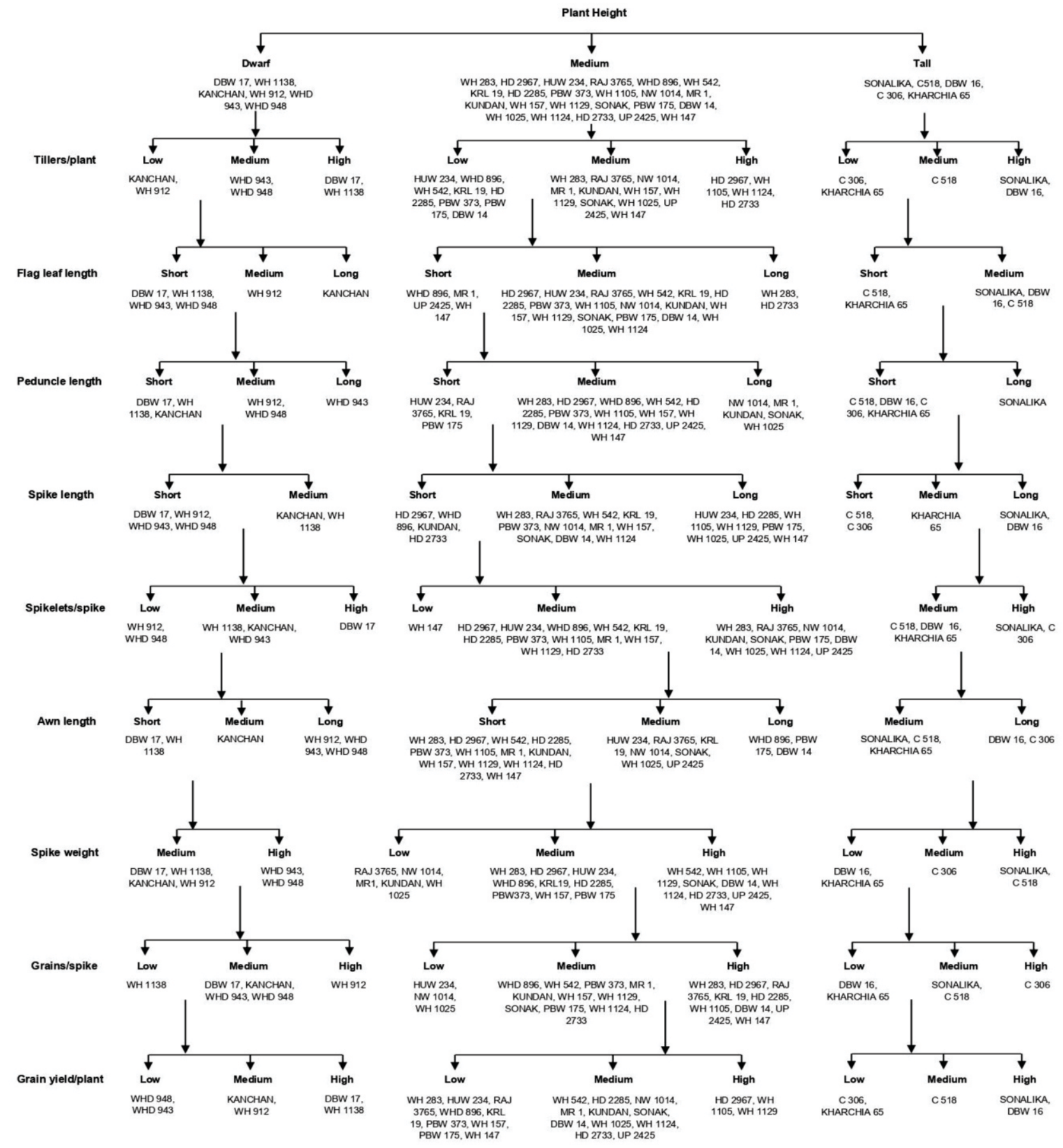

Fig. 1 : Flow chart showing grouping of 34 wheat varieties on the basis of morphological traits.

some dwarf and an intermediate stable group is always there with maximum population. All the varieties in this study were also categorised in three groups [dwarf $(<90 \mathrm{~cm})$, medium $(90-105 \mathrm{~cm})$ and tall $(>105 \mathrm{~cm}$ )]. Six varieties (DBW 17, WH 1138, Kanchan, WHD 912, WHD 943 and WHD 948) were dwarf, five cultivars (Sonalika, C 518, DBW 16, C 306 and Kharchia 65) were tall and remaining had medium height. In a previous study, wheat varieties were categorized in five groups as very short, short, medium, long and very long (Maity and Das, 2015). A variable range in plant height among wheat varieties grown under rain-fed conditions was also obtained by Tomar et al. (2016).

For flag leaf length, ten varieties (DBW 17, WH 1138, WHD 943, WHD 948, WHD 896, MR 1, UP 2425, WH 147, C 518 


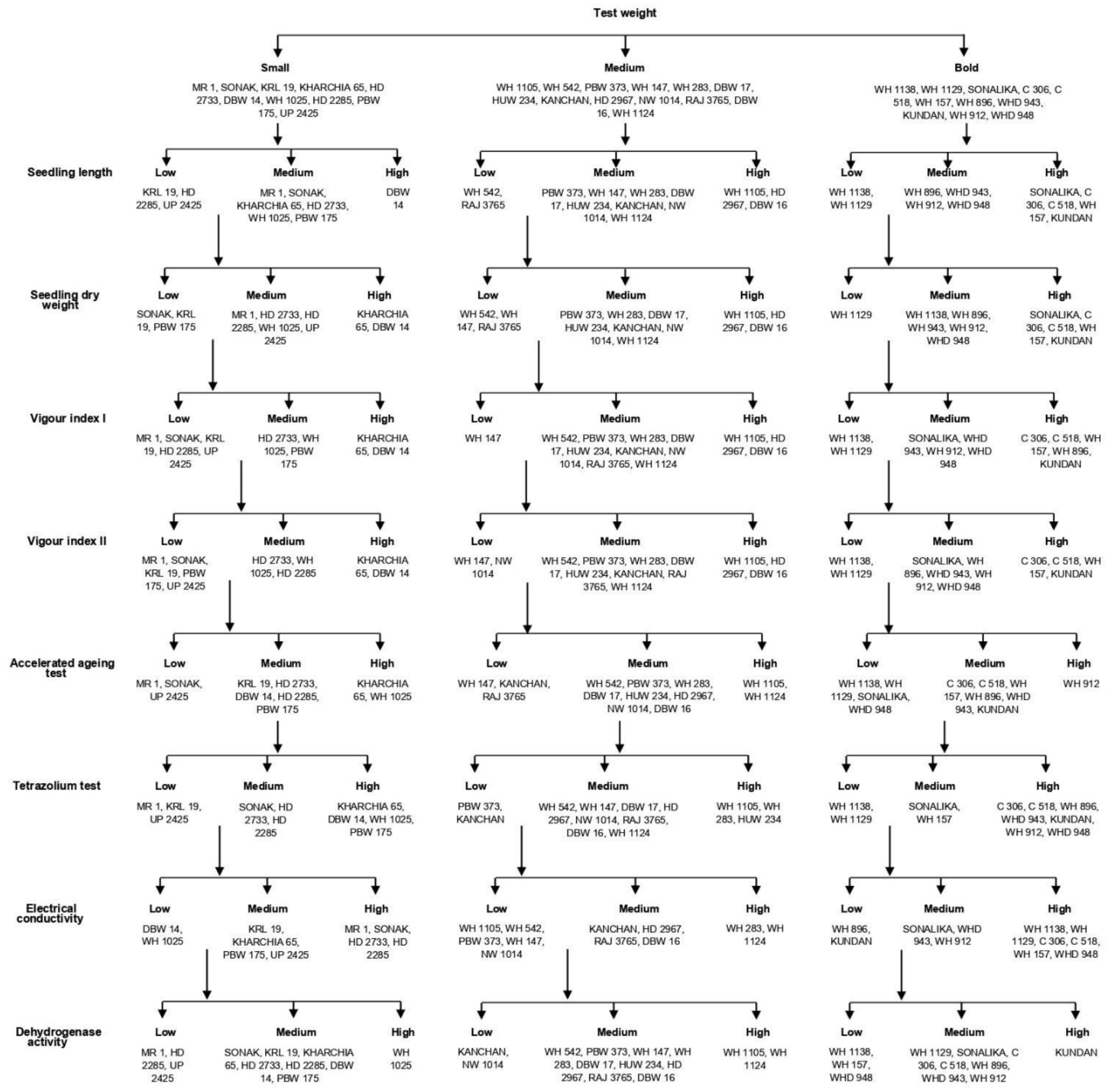

Fig. 2 : Flow chart showing grouping of 34 wheat varieties on the basis of seed vigour traits.

and Kharchia 65) showed short flag leaf length $(<25 \mathrm{~cm}), 21$ varieties (WH 912, HD 2967, HUW 234, RAJ 3765, WH 542, KRL 19, HD 2285, PBW 373, WH 1105, NW 1014, Kundan, WH 157, WH 1129, Sonak, PBW 175, DBW 14, WH 1025, WH 1124, Sonalika, DBW 16 and C 306) had medium sized $(25-35 \mathrm{~cm})$ flag leaf and the remaining three (Kanchan, WH 283 and HD 2733) had long flag leaf $(>35 \mathrm{~cm})$.

The floral characters like peduncle length, spike length and awn length were also used to characterize thirty-four genotypes. For peduncle length, eleven varieties were characterized as short $(<35 \mathrm{~cm})$, sixteen varieties had medium $(35-40 \mathrm{~cm})$ and seven varieties (WHD 943, NW 1014, MR 1, Kundan, Sonak, WH 1025 and Sonalika) had long peduncle (>40 $\mathrm{cm})$. Peduncle has an appreciable role in grain filling event as it owns a significant greener area to provide photosynthetic help and eventually better grain filling under stress conditions (Tomar et al., 2016). Börner et al. (2002) suggested that length of peduncle have significance in disease escape and breeding for resistance to ear head related diseases. Genotypes having long 


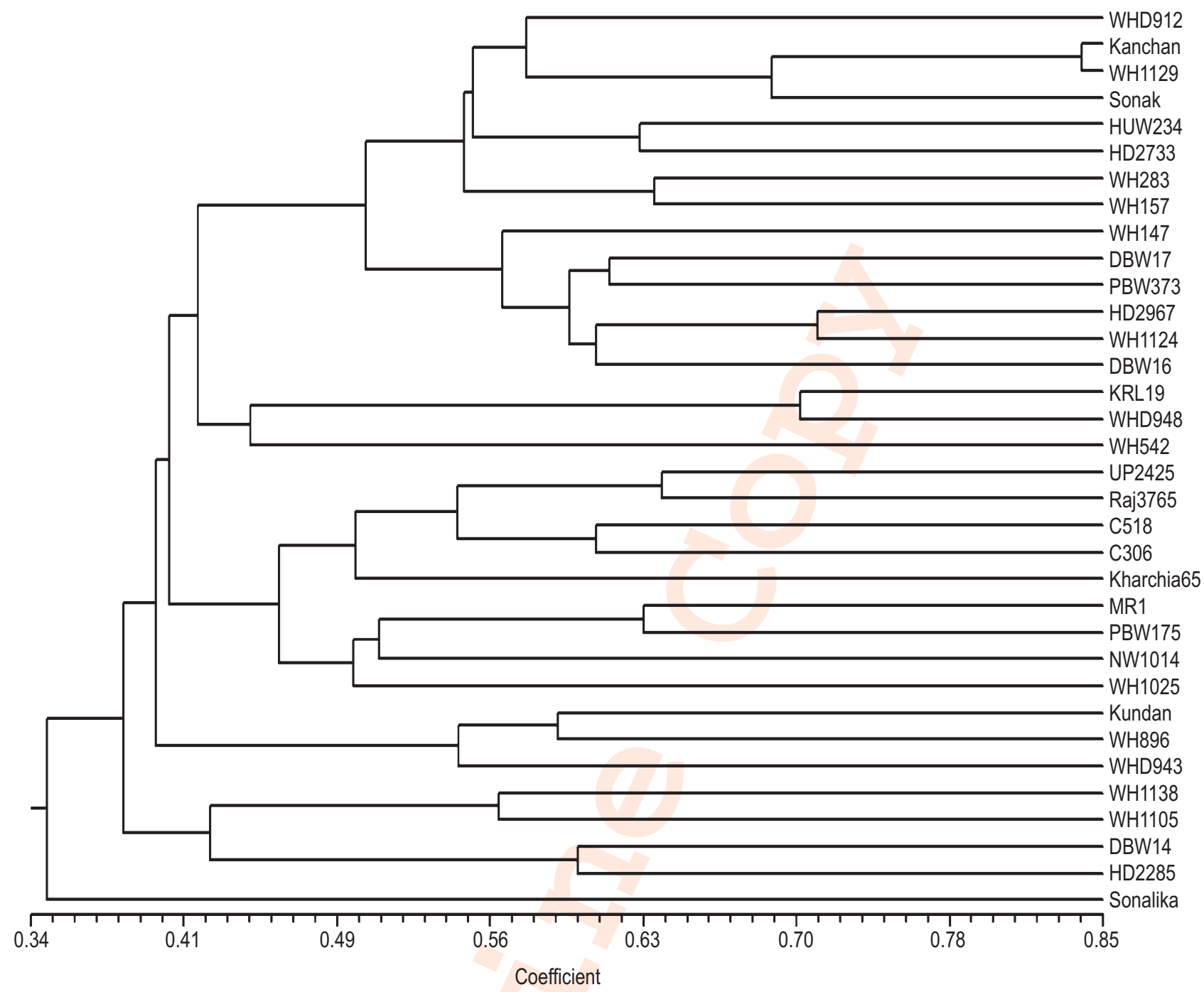

Fig. 3 : Dendrogram based on molecular data generated from 21 SSR markers.

peduncle are less susceptible to such diseases. Here, in the present study, seven varieties were classified to have longer peduncles. These varieties could be screened for any significant ability to tolerate ear head related diseases which might be useful in establishing their use in future breeding program.

Spike length was also used as one of the criterion for characterization, the grouping of varieties is as follows: short spike length $(<10 \mathrm{~cm})$ was observed in ten varieties, fourteen genotypes had medium (10-12 cm) and ten genotypes (HUW 234, HD 2285, WH 1105, WH 1129, PBW 175, WH 1025, UP 2425, WH 147, Sonalika and DBW 16) showed longer spikes (>12 $\mathrm{cm})$. Knežević et al. (2013) also observed difference in spike lengths of wheat genotypes and suggested that genetic factors have more impact on spike length than environmental factors.

Awns are filiform bristle like expansions of lemma settle in winter wheat and some cereals (Rebetzke et al., 2016). On the basis of awn length, the classification resulted in three categories, out of 34 varieties, eight varieties (WH 912, WHD 943, WHD 948, WHD 896, PBW 175, DBW 14, DBW 16 and C 306) had longer awns $(\geq 10 \mathrm{~cm})$, fifteen varieties had short awns $(\leq 7 \mathrm{~cm})$ and the rest had medium sized awns $(7.1-9.9 \mathrm{~cm})$. Awns are important structures and have reported $60 \%$ contribution in total spike photosynthesis (Teare et al., 1972). Awns increase the area of spike and length of awns vary, some durum wheat varieties have longer awns than bread wheat (Motzo and Giunta, 2002). The results of the present study are in parallel to their findings and all the durum and a few bread wheat genotypes exhibited longer awn than others.

Grouping based on spikelet weight had categorised all thirty-four genotypes in three groups such as seven varieties were of low spikelet weight $(<2 \mathrm{~g})$, fourteen varieties had medium weight (2-3 g) and remaining genotypes (WHD 943, WHD 948, 
WH 542, WH 1105, WH 1129, Sonak, DBW 14, WH 1124, HD 2733, UP 2425, WH 147, Sonalika and C 518) recorded high spikelet weight $(>3 \mathrm{~g})$. It is believed that the spikelet is basic unit of inflorescence in grasses and critical for the reproductive achievement and final yield. Three types of groups were identified based on spikelet number per spike as low (<16), medium (16-20) and high (>20). Four varieties had lower number of spikelets whereas thirteen varieties (DBW 17, WH 283, RAJ 3765, NW 1014, Kundan, Sonak, PBW 175, DBW 14, WH 1025, WH 1124, UP 2425, Sonalika and C 306) had high number of spikelets per spike.

Grain yield is a major parameter which decides the commercial success of a variety. Varieties with higher yield are selected and yield itself is determined by various other traits like number of grains per spike, thousand grain weight and source sink relationship etc. Among yield attributing characters, productive tiller is determining trait, as number of spike bearing tillers directly impact the final yield (Pandey et al., 2017). Regarding the number of tillers per plant, genotypes were characterized into high $(>15)$, medium $(12-15)$ and low $(<12)$. Twelve varieties had less number of tillers per plant and higher number was produced by eight genotypes (DBW 17, WH 1138, HD 2967, WH 1105, WH 1124, HD 2733, Sonalika and DBW 16) and the remaining had medium number of tillers. Xie et al. (2016) observed large genotypic variability in tillering and concluded that genotypes with higher capacity of tillering can be selected towards yield enhancement. In the present study, it was observed that the varieties showing higher tillering capacity were either tall or medium in plant height. This shows a connecting line with previous studies (Ajmal et al., 2009; Gulnaz et al., 2011; Bhutto et al., 2016) suggested a positive and significant correlation between plant height and tiller number per plant.

Three main groups were created on the basis of grain number per spike. First group had less than 30 grains, second had 30 to 50 grains and third group had more than 50 grains per spike. Genotypes WH 912, WH 283, HD 2967, RAJ 3765, KRL 19, HD 2285, WH 1105, DBW 14, UP 2425, WH 147, C 306 and DBW 16 had higher number of grains contrasting to cultivars WH 1138 , HUW 234, NW 1014, WH 1025, DBW 16 and Kharchia 65 which possessed lesser number of grains. Zi et al. (2018) also obtained varietal variability in kernel number in the varieties of wheat and stated that yield and related traits were determined by both the cultivar and environment.

The grain yield in wheat is the ultimate product of ear heads, in association with grain number per head and grain weight per unit area. Shahwani et al. (2014) had discussed about grain yield and seed size and interaction among these two while identifying high yielders in their own study. Similar results were obtained in the present study and 34 varieties were categorised into three groups on the basis of grain yield per plant. High yielder group ( $>35 \mathrm{~g}$ ) included the genotypes DBW 17, WH 1138, HD
2967, WH 1105, WH 1129, Sonalika and DBW 16 whereas the genotypes WH 157, C 306, WHD 948, WHD 943, WH 283 and RAJ 3765 were categorised as low yielders $(<25 \mathrm{~g})$. The remaining genotypes were grouped into the category of moderate $(25-35 \mathrm{~g})$ yielders. The identified high yielders could be suggested for commercially cultivation.

Seed weight is a variable entity and closest trait to yield a particular variety. The classification based on thousand seed weight grouped thirty-four genotypes in three major groups. Genotypes MR 1, Sonak, KRL 19, Kharchia 65, HD 2733, DBW 14, WH 1025, HD 2285, PBW 175 and UP 2425 had low test weight as compared to varieties WH 1138, WH 1129, Sonalika, C 306, C 518, WH 157, WH 896, WHD 943, Kundan, WH 912 and WHD 948 which had high test weight. The remaining varieties had medium seed weight. A lot of studies support the fact of variability in seed weight and is braced by the fact that this trait is influenced by many factors viz. genotypic effect, environment of growth, position of seed on inflorescence and a lot more to list (Wulff, 1986; Fenner, 1992; Obeso, 2012; Kołodziejek, 2017). Wang et al. (2012) studied the variability in thousand kernel weight of modern varieties and landraces of wheat and concluded that thousand kernel weight of modern varieties is more than that of landraces. In the present study also, variation was observed among the varieties which indicated that the older varieties have bolder seeds as compared to recently released varieties. Bold seeds are generally presumed to be more vigorous than small seeds. Various studies have found that boldness of seed works in initial stages of seed germination and seedling development (Stanton, 1984; Saeed et al., 2000; Larsen and Andreasen, 2004; Ahirwar, 2012) but only few are there to support the role of large seed in plant development in later stages upto yield (Royo et al., 2006; Shahwani et al., 2014).

Seven-days-old seedling of wheat is purely the product of seed as is feeded by the seed reserves and it truely determines the vigour of that seed. Characters associated to seedling are, thus important to study while assessing seed vigour. Based on seedling length, seven varieties were grouped as small $(<20 \mathrm{~cm})$, 18 as medium $(20-25 \mathrm{~cm})$ whereas nine varieties (DBW 14, WH 1105, HD 2967, DBW 16, Sonalika, C 306, C 518, WH 157 and Kundan) were grouped as long $(>25 \mathrm{~cm})$. On the basis of seedling dry weight, categories formed were low (>120 mg), medium (120$170 \mathrm{mg}$ ) and high (>170 mg). Varieties identified with high seedling weight were Kharchia 65, DBW 14, WH 1105, HD 2967, DBW 16, Sonalika, C 306, C 518, WH 157 and Kundan. Narayanan et al. (2014) studied root related traits and Singh et al. (2017) studied seedling dry weight, seedling length and vigour indices in wheat and observed significant variability.

All the varieties classified on the basis of vigour index-I as low (<1700), medium (1700-2200) and high (>2200). Eight varieties had low values, ten varieties (Kharchia 65, DBW 14, WH 1105, HD 2967, DBW 16, C 306, C 518, WH 157, WH 896 and 
Kundan) had high vigour index and the remaining sixteen were grouped to be moderately vigourous. Likewise, on the basis of vigour index-II, nine cultivars (DBW 16, C 518, HD 2967, WH 157, Kharchia 65, DBW 14, C 306, WH 1105 and Kundan) reported high values $(>15)$ while same number of genotypes showed low values $(<10)$. The remaining cultivars had medium values for vigour index-II (10-15).

Stress tests brings out the real potential and also help in determination of storability of seed. In case of wheat, accelerated ageing test was concluded to be adequate for assessing seed vigour potential (Fanan et al., 2006). Stress bearing ability of seeds of all genotypes was evaluated by Accelerated Ageing (AA) test. Ten varieties (MR 1, Sonak, UP 2425, WH 147, Kanchan, RAJ 3765, WH 1138, WH 1129, Sonalika and WHD 948) could not bear the stress and showed low germination percentage after accelerated ageing $(<40 \%)$ while comparing with Kharchia 65 , WH 1025, WH 1105, WH 1124 and WH 912 showed high germination $(>50 \%)$. The varieties characterized with high germination after accelerated ageing can be identified as good storers of seed vigour and were more vigorous. Accelerated ageing test provide conditions which the seed will face under natural ageing, hence, it is a more reliable test to depict the vigour of a given seed lot.

Electrical conductivity of seed leachates together with tetrazolium test provides a set of biochemical tests for prediction of seed vigour of a given variety. Matthews and Bradnock (1967) elaborated procedure of electrical conductivity test in pea and further it was used in several other species with slight modifications. This test works on the principle of membrane damage during the process of deterioration and says that more damaged and less vigorous seeds will leach out more of their solutes and ions through the plasma membrane (Marcos-Filho, 2015). Difference in the values indicated variability on the basis of this test and all the thirty-four genotypes were grouped in distinct classes based on the values of electrical conductivity i.e., low, medium and high $\left(<120,120-150\right.$ and $>150 \mu \mathrm{sm}^{-1}$ seed $^{-1}$ respectively). The cultivars under low value group included DBW 14, WH 1025, WH 1105, WH 542, PBW 373, WH 147, NW 1014, WH 896 and Kundan showed high membrane integrity in contrast to varieties MR 1, Sonak, HD 2733, HD 2285, WH 283, WH 1124, WH 1138, WH 1129, C 306, C 518, WH 157 and WHD 948 having higher values of $\mathrm{EC}$ indicating their poor quality and storability. Fessel et al. (2006) aforementioned in corn, a downturn in seed vigour had a direct correlation to increased ion leakage and approved a close relation between membrane integrity and vigour loss. Matthews and Powell (2006) suggested a correlation between readings of conductivity and field emergence and said that by analysing single seed leachate conductivity, standard germination and seed vigour could be indicated. By measuring EC, a role could be assigned to it similar to the tests based on ageing such as accelerated ageing, cold test and controlled deterioration test.
Seed vigour testing through standard methods consumes approximately seven to more days and requires intensive labour. Hence, a lot of interest is being invested towards development of rapid seed vigour testing methods (Wen et al., 2018), and tetrazolium is the one of the quicker method replacing standard germination test. Amoêdo and Ferraz (2017) used tetrazolium staining to characterise tree seeds and obtained two categories, bright red or pink as living tissues and off white to yellowish as dead seeds. In the present study, percentage of viable seeds was obtained after counting the number of pink or red coloured seeds of every variety, high percentage of viable seeds was obtained for Kharchia 65, DBW 14, WH 1025, PBW 175, WH 1105, WH 283, HUW 234, C 306, C 518, WH 896, WHD 943, Kundan, WH 912, WHD 948 (>95\%) and lower percentage for MR 1, KRL 19, UP 2425, PBW 373, Kanchan, WH 1138 and WH 1129. The remaining genotypes had moderate level of viability (90-95\%). Grzybowski et al. (2012) also found usefulness of this test in barley for viability testing.

The activity of dehydrogenase enzymes is useful in characterisation of different genotypes as higher activity of this enzyme correlates to high viability and vigour of seed (Nautiyal and Joshi, 1991; Yanping et al., 2000). These enzymes are oxidoreductases, which perform functions of saccharide catabolism and play an important role in anerobic metabolism during germination process in seeds (Guo et al., 2011). On the basis of this test, four genotypes (WH 1025, WH 1105, WH 1124 and Kundan) showed very high activity $(>0.4)$ and eleven varieties (HD 2733, WHD 943, WH 283, DBW 17, WH 896, DBW 16, HD 2967, DBW 14, HUW 234, PBW 175 and Kharchia 65) had high DHA activity (0.3-0.4) whereas genotypes (WH 157, UP 2425, WH 1138, Kanchan, NW 1014, HD 2285, MR 1 and WHD 948 ) had low activity (<0.2). The remaining genotypes were found to have moderate level of DHAactivity.

Genetic diversity is imperative to make any crop and seed improvement programme effective. DNA based molecular markers act as a versatile resource to study diversity and variability as they obviously permit comparison of genetic material keeping away from any environmental effect on gene expression (Kalpana et al., 2004). Breeders use molecular markers to build the accuracy of selection for best preliminary combinations. Selection aided by SSRs brings about huge improvement in breeding efficiency by diminishing trial and error part of breeding process, and also confirms cost and time savings.

Forty-five SSR markers were utilized in the present investigation, out of which twenty-one $(46.66 \%)$ primer pairs were clearly amplified (Table 2$)$. Seventeen $(80.95 \%)$ primers out of those twenty-one amplified primer sets showed polymorphism among thirty -our wheat genotypes with alleles per primer ranging from 1-4, and the total amplified allele number was 46 with PIC value of SSRs varied from 0.1 to 0.65 (Table 2). Cheng et al. 
(2016) conducted a similar estimation of SSR polymorphism with 160 candidate primer sets by estimating amplification (55\%), polymorphism (73.86\%), allele range (1-6) and PIC value (0.050.64 ) and suggested the use of this information for further selection and designing of primer sets. Xia et al. (2017) identified a direct correlation between genome size and number of SSR Ioci while a negative interaction between genome size and SSR density was also concluded by them. Based on motif length seven types of SSR loci, can be obtained ranging from monomers to heptamers. Some SSR markers proved to be very informative as they provided higher PIC values viz. Xgwm 46 (0.65), Xgwm 146 $(0.60)$ and Xgwm 112 (0.54) (Table 2). These markers have been previously reported to produce higher polomorphism in a study conducted by Raj et al. (2017). Nefzaoui et al. (2014) recorded a total of 44 alleles using 9 markers, Salem et al. (2008) recorded a total of 48 alleles using 15 markers while Sheoran et al. (2015) recorded a total of 86 alleles with 36 markers. However, some researchers found high number of total alleles viz. Emon et al. (2010) reported 234 alleles using 36 markers and Salehi et al. (2018) found 180 alleles with an average of 9 alleles per locus in 21 genotypes using only 20 markers.

An UPGMA phylogenetic tree was prepared on the basis of SSR data (Fig. 3). The clustering was based on Jaccard's similarity coefficient and dendrogram has extensively partitioned a single variety Sonalika as an outgroup from a huge cluster of 33 genotypes at a similarity value of 0.348 . Further, sub clustering of major cluster at similarity value 0.41 has given five clusters. $1^{\text {st }}$ cluster contained 14 genotypes (WHD 912, Kanchan, WH 1129, Sonak, HUW 234, HD 2733, WH 283, WH 157, WH 147, DBW 17, PBW 373, HD 2967, WH 1124 and DBW 16), $2^{\text {nd }}$ cluster had 3 genotypes (KRL 19, WHD 948 and WH 542), $3^{\text {rd }}$ cluster contained 8 genotypes (UP 2425, RAJ 3765, C 518, C 306, Kharchia 65, MR 1 , PBW 175 and NW 1014), $4^{\text {th }}$ cluster had 3 genotypes (Kundan, WH 896 and WHD 943) and $5^{\text {th }}$ cluster had 4 genotypes (WH 1138 , WH 1105, DBW 14 and HD 2285).

Based on the Jaccard's similarity coefficient, relations were drawn amongst thirty-four wheat genotypes and similarity coefficient varied from 0.34 to 0.86 . Maximum similarity was observed between Kanchan and WH 1129 and the most distant genotypes observed were WH 542 and WH 1025. Some genotypes from same geographical regions were grouped together such as Raj 3765, MR1 and Kharchia 65 from Rajasthan and HUW 234 and NW 1014 from Uttar Pradesh whereas other genotypes dispersed randomly among different clusters. Two varieties (WH 896 and WHD 943) out of four durum wheat varieties were placed under same cluster while the other two were scattered among different clusters with bread wheat. Lower magnitude of genetic diversity among cultivated wheat varieties and grouping of durum genotypes with aestivum was also reported (Raj et al., 2017). Restricted genetic diversity between different species and within a single species is due to the nature of wheat as it is an allohexaploid developed by crosses between three highly interrelated diploid species, and the process of poplyploidization limits the genetic variability (Venske et al., 2019).

An attempt was made to work out any correlation between the geographical region from which the genotype originated and different groups formed on the basis of morphological and seed related traits. The varieties from Haryana showed their distribution under all the categories of plant height. However, most of the varieties from this region have medium plant height besides some varieties with tall and dwarf stature. All the dwarf varieties were from Haryana, except Kanchan which belong to Delhi. The varieties from Rajasthan, Delhi, Uttar Pradesh, Uttarakhand and Punjab were grouped together with some exceptions viz. Kharchia 65 , Kanchan and Sonalika. All the high yielders were from Haryana region except two, one from Punjab (Sonalika) and another from Delhi (HD 2967) region. Similarly, all the bold seeded varieties belonged to Haryana, except Sonalika from Punjab and Kundan from Delhi. The group of varieties with good storing qualities with respect to low electrical conductivity is solely dominated by varieties from Haryana region, except for Kharchia 65 which relates to Rajasthan. The overall grouping based on morphological characters and seed vigour traits was not dominated by their geographical locations.

Phylogenetic tree based on molecular data was analysed to classify genotypes according to their geographical locations. Genotypes from Rajasthan and Uttar Pradesh were clustered into distinct groups. On the other hand, genotypes from Haryana, Punjab and Delhi were highly scattered and were present in almost all the clusters. None of the classifications could clearly differentiate the genotypes with respect to their geographical locations and similarity among them was independent of the geography to which they are best adapted. These results are similar to that reported by Kumar et al. (2013) in guar and Raj et al. (2017) in wheat.

All the genotypes under this study could most suitably be classified under three time scales according to their year of release (Table 1). The varieties released before 1980's (old), between 1980-2000 (middle) and after 2000 (recent). The old varieties were taller when compared to recent ones. Yield increased as we move towards recent years, most of the low yielders were present in the era before 1980's. Most of the old varieties had bold seeds along with two advanced lines (most recent) and all the durum genotypes. Seedling dry weight, seedling length and vigour indices also showed higher values in old varieties, suggesting their high seed vigour potential. While assessing the dendrogram for diversity based on chronology, three out of five old varieties were clustered together consecutively, while one (Sonalika) was out grouped and could not be placed in any of the clusters. But the varieties from middle years and recent ones were unable to keep themselves in pace 
with chronology while clustering. Somehow, the morphological and seed characters have tried to classify varieties in chronological order at least for few traits. Tendency of plant breeders towards dwarfing of wheat was clearly seen in this chronology based pattern followed by the studied genotypes. Yield of the varieties increased and seed vigour potential decreased according to our assessment. The reason behind this might be that when the yield increases, then there is a possible tendency for the increase in grains per spike and individual seed weight decreases. But the trait of seed weight/boldness should be emphasized in the current era of climatic uncertainty to tackle with various types of abiotic stresses because bold seeds have larger endosperm which better feeds the embryo better during germination (Shahwani et al., 2014). Moreover, the characters like biomass production, seed boldness and seedling vigour in which old varieties were found superior, play an important role in stress tolerance of a crop as well as crucial for maintaining the productive capacity of agroecosystem by residue production and nutrient cycling. New genotypes are developed by prolonged breeding with emphasize only on 'grain production' suitable for intensive and industrialized management. Carranza-Gallego et al. (2018) concluded that modern wheat varieties are responsible for degradation of rainfed agroecosystem in Spain and suggested that old varieties can be used to restore agricultural ecosystem. The results of the present study also direct towards the benefits of older varieties and their possible use in sustaining the agroecosystem which is presently struggling with soil fertility degradation, environmental stresses and overuse of agrochemicals.

The overall inference from the present study revealed that there were some trends for different traits suggesting that breeding programs emphasize more towards improvement of yield potential and other associated characters. Seed related traits have shown a decrease in previous decades or somewhat, stagnation in recent years. This study demonstrates an aspect to be contemplated in current and future breeding programs for a sustainable improvement in wheat production. Moreover, SSR marker analysis, being most economical and less time consuming, appears to be the best technique to discriminate among different wheat accessions, and the observations of the present study can be utilized further for advancing a wellcharacterized approach dependent on assessment and characterization of genetic variation in wheat.

\section{Acknowledgment}

Authors are highly thankful to the Head, Department of Seed Science and Technology for providing necessary facilities.

\section{References}

Abdul-Baki, A.A. and J.D. Anderson: Vigour determination in soybean seed by multiple criteria. Crop Sci., 13, 630-633 (1973).
Ahirwar, J.R.: Effect of seed size and weight on seed germination of Alangium lamarckii, Akola, India. Res. J. Rec. Sci., 1, 320-322 (2012).

Ajmal, S.U., N. Zakir and M.Y. Mujahid: Estimation of genetic parameters and character association in wheat. ARPN J. Agric. Biolog. Sci., 1, 15-18 (2009)

Amoêdo, S.C. and I.D.K. Ferraz: Seed quality evaluation by tetrazolium staining during a desiccation study of the recalcitrant seeds of Carapa guianensis Aubl. and Carapa surinamensis Miq-Meliaceae. Afr J. Agric. Res., 12, 1005-1013 (2017).

Anderson, J.A., G.A. Churchill, J.E. Autrique, S.D. Tanksley and M.E. Sorrells: Optimizing parental selection for genetic linkage maps. Genome, 36, 181-186 (1993).

AOSA: Seed Vigour Testing Handbook. Association of Official Seed Analyst PublicationAOSAHandbook 32 (1983).

Bhutto, A.H., A.A. Rajpar, S.A. Kalhoro, A. Ali, F.A. Kalhoro, M. Ahmed, S. Raza and N.A. Kalhoro: Correlation and regression analysis for yield traits in wheat (Triticum aestivum L.) genotypes. Nat. Sci., 8, 96-104 (2016).

Börner, A., E. Schumann, A. Fürste, H. Cöster, B. Leithold, M.S. Röder and W.E. Weber: Mapping of quantitative trait loci determining agronomic important characters in hexaploid wheat (Triticum aestivum L.). Theor. Appl. Genet., 105, 921-936 (2002).

Carranza-Gallego, G., G.I. Guzmán, D. Soto, E. Aguilera, I. Villa, J. Infante-Amate, A. Herrera and M. González de Molina: Modern wheat varieties as a driver of the degradation of spanish rainfed mediterranean agroecosystems throughout the $20^{\text {th }}$ century. Sustainability, 10, 3724 (2018).

Chauhan, K., C. Babariya, A. Hirpara and P. Babariya: Characterization of bread wheat (Triticum aestivum L.) genotypes through seed morphology. J. Pharmacogn. Phytochem., 9, 344-347 (2020).

Cheng, J., Z. Zhao, B. Li, C. Qin, Z. Wu, D.L. Trejo-Saavedra, X. Luo, J. Cui, R.F. Rivera-Bustamante, S. Li and K. Hu: A comprehensive characterization of simple sequence repeats in pepper genomes provides valuable resources for marker development in capsicum. Sci. Rep., 6, 18919 (2016).

Clark, R.M., E. Linton, J. Messing and J.F. Doebley: Pattern of diversity in the genomic region near the maize domestication gene tb1. Proc. Natl. Acad. Sci. USA., 101, 700-707 (2004).

Emon, R.M., J.P. Gustafson, H. Nguyen, T. Musket, M. Jahiruddin, M.A. Islam, M.S. Haque, M.M. Islam, S.N. Begum and M.M. Hassan: Molecular marker-based characterization and genetic diversity of wheat genotypes in relation to boron use efficiency. Indian. J. Genet. Pl. Br., 70, 339-348 (2010).

Fanan, S., P.F. Medina, T.C. Lima and J. Marcos-Filho: Evaluation of wheat seeds vigor by accelerated and cold tests. Rev. Bras. Sementes., 28, 152-158 (2006).

Fenner, M.: Environmental influences on seed size and composition. Hortic. Rev., 74, 385-392 (1992).

Fessel, S.A., R.D. Vieira, M.C.P. deCruz, R.C. dePaula and M. Panobianco: Electrical conductivity testing of corn seeds as influenced by temperature and period of storage. Pesqui. Agropecu. Bras., 41, 1551-1559 (2006).

Feledyn-Szewczyk, F., J. Kuś, J. Stalenga, A. K. Berbeć and P. Radzikowski: The role of biological diversity in agroecosystems and organic farming. In: Organic Farming - A Promising Way of Food Production. Intech Open Publishing House, pp. 59 (2016).

Grewal, S., P. Kharb, R. Malik, S. Jain and R.K. Jain: Assessment of genetic diversity among some Indian wheat cultivars using random 
amplified polymorphic DNA (RAPD) markers. Indian J Biotechnol., 6, 18-23 (2007).

Grzybowski, C.R.S., O.C. Ohlson, R.C. daSilva and M. Panobianco: Viability of barley seeds by the tetrazolium test. Rev. Bras. Sementes., 34, 47-54 (2012).

Gulnaz, S., M. Sajjad, I. Khaliq, A.S. Khan and S.H. Khan: Relationship among coleoptile length, plant height and tillering capacity for developing improved wheat varieties. Int. J. Agric. Biol., 13, 130 133 (2011).

Guo, H., H. Zhang, Y. Li, J. Ren, X. Wang, H. Niu and Yin: Identification of changes in wheat (Triticum aestivum L.) seeds proteome in response to anti-trx s gene. PloS ONE, 6, e22255 (2011).

ISTA: International rules for seed testing. Seed. Sci. Technol., 23, 1-334 (1999)

Kalpana, J., P.C. Warude and P. Bhushan: Molecular markers in herbal drug technology. Curr Sci., 87, 159-165(2004).

Kittock, D.L. and A.G. Law: Relationship of seedling vigour to respiration and tetrazolium chloride reduction by germinating wheat seeds. Agron. J., 60, 286-288 (1968).

Knežević, D., A. Paunović, M. Madić, S. Tanasković, J. Knežević and A. Šekularac: Phenotypic variability of primary spike length in winter wheat (Triticum aestivum L.). Genet. PI. Breed. Seed. Prod., 48, 269-273 (2013).

Kołodziejek, J.: Effect of seed position and soil nutrients on seed mass, germination and seedling growth in Peucedanum oreoselinum (Apiaceae). Sci. Rep., 7, 1959 (2017).

Kumar, S., U.N. Joshi, V. Singh, J.V. Singh and M.L. Saini: Characterization of released and elite genotypes of Guar [Cyamopsis tetragonoloba (L.) Taub.] from India proves unrelated to geographical origin. Genet. Resour. Crop. Evol., 60, 2017-2032 (2013).

Larsen, S.U. and C. Andreasen: Light and heavy seeds differ in germination percentage and mean germination thermal time. Crop. Sci., 44, 1710-1720 (2004).

Li, M.Y., F. Wang, Q. Jiang, J. Ma and A.S. Xiong: Identification of SSRs and differentially expressed genes in two cultivars of celery (Apium graveolens L.) by deep transcriptome sequencing. Hortic. Res., 10, 1-9 (2014).

Maity, S. and S. Das: Morphological characterization of bread wheat (Triticum aestivum L.) based on distinctness, uniformity and stability (DUS) test. J. Agric. Technol., 2, 101-106 (2015).

Marcos-Filho, J.: Seed vigor testing: an overview of the past, present and future perspective. Sci. Agric., 72, 363-374 (2015).

Matthews, S. and A. Powell: Electrical conductivity vigour test: Physiological basis and use. Seed. Test. Int., 131, 32-35 (2006).

Matthews, S. and W.T. Bradnock: The detection of seed samples of wrinkle-seeded peas (Pisum sativum L.) of potentially low planting value. Proc. Int. Seed. Test. Assoc., 32, 553-563 (1967).

Mollasadeghi, V., A.G. Eshghi, R. Shahryari and R. Serajamani: Study on morphological traits of bread wheat genotypes and their relation with grain yield, under the condition of drought stress after anthesis and normal irrigation. Intl. J. Farm. Alli. Sci., 2, 1284-1291 (2013).

Moore, R.P.: Tetrazolium stain for assessing seed quality. In: Seed Ecology. pp. 347-366 (1973).

Motzo, R. and F. Giunta: Awnedness affects grain yield and kernel weight in near-isogenic lines of durum wheat. Crop. Pasture. Sci., 53, 1285-1293 (2002).

Narayanan, S., A. Mohan, K.S. Gill and P.V.V. Prasad: Variability of root traits in spring wheat germplasm. PloS ONE, 9, 100317 (2014).
Nautiyal, P.C. and Y.C. Joshi: Storage of Rabi/Summer groundnut (Arachis hypogeal L.) with calcium chloride for prolonged seed viability and vigour. Trop. Sci., 31, 21-26 (1991).

Nefzaoui, M., S.M. Udupa, M.S. Gharbi, M. Bouhadida and D. Iraqi: Molecular diversity in Tunisian durum wheat accessions based on microsatellite markers analysis. Roman. Agrl. Res., 31, 33-39 (2014).

Obeso, J.R.: Mineral nutrient stoichiometric variability in Hedera helix (Araliaceae) seeds. Ann. Bot., 109, 801-806 (2012).

Pandey, G., L. Yadav, A. Tiwari, H.B. Khatri, S. Basnet, K. Bhattarai, B. Gyawali, N. Rawal and N. Khatri: Analysis of yield attributing characters of different genotypes of wheat in Rupandehi Nepal. Int. J. Agric. Environ. Biotechnol., 2, 2374-2379 (2017).

Raj, R.S., Y.S. Vyas, V.K.M. Baranda, M.N. Joshi, S.N. Tyagi and S.B. Bagatharia: Ascertaining narrow genetic base in commercial accessions of wheat commonly grown in Gujarat via molecular markers. Electron. J. Plant Breed., 8, 558-565 (2017).

Rebetzke, G.J., D.G. Bonnett and M.P. Reynolds: Awns reduce grain number to increase grain size and harvestable yield in irrigated and rainfed spring wheat. J. Exp. Bot., 67, 2573-2586 (2016).

Rohlf, F.J.: NTSYS-pc: Numerical taxonomy and multivariate analysis system, version 2.1. Exeter Software: Setauket, NY (2000).

Royo, C., A. Ramdani, M. Moragues and D. Villegas: Durum wheat under Mediterranean conditions as affected by seed size. J. Agron. Crop. Sci., 192, 257-266 (2006).

Saeed, S., S. Shahid and S. Shaukat: Effect of seed size on germination, emergence, growth and seedling survival of Senna occidentalis Link. Pak. J. Biol. Sci., 3, 292-295 (2000).

Saghai-Maroof, M.A., K.M. Soliman, R.A. Jorgensen and R.W. Allard: Ribosomal DNA spacer-length polymorphisms in barley: Mendelian inheritance, chromosomal location and population dynamics. Proc. Natl. Acad. Sci. USA., 81, 8014-8019 (1984).

Salehi, M., A. Arzani, M. Talebi and A. Rokhzadi: Genetic diversity of wheat wild relatives using SSR markers. Genetika, 50, 131-141 (2018).

Salem, K.F.M., A.M. El-Zanaty and R.M. Esmail: Assessing wheat (Triticum aestivum L.) genetic diversity using morphological characters and microsatellite markers. World. J. Agric. Res., 4, 538-544 (2008).

Shahwani, A.R., S.U. Baloch, S.K. Baloch, B. Mengal, W. Bashir, H.N. Baloch, R.A. Baloch, A.H. Sial, A.I. Salih, K. Sabiel-Razzaq, A.A. Shahwani and A. Mengal: Influence of seed size on germinability and grain yield of wheat (Triticum aestivum L.) varieties. J. Nat. Sci. Res., 4, 147-155(2014).

Sheoran, S., P. Sharma, V. Singh, S. Pawar, D. Sharma, N. Jain, R. Kumar, V. Thakur, G.C. Pandey, R. Malik, R. Tiwari, V. Tiwari, R.K. Gupta and I. Sharma: Assessment of genetic diversity in elite wheat genotypes using simple sequence repeat and quality protein markers. J. Wheat. Res., 7, 18-26 (2015).

Singh, I., P.K. Rai, A. Dayal, D.K. Srivastav, N. Kumari and V. Dugesar: Effect of pre-sowing invigoration seed treatments on germination behaviour and seedling vigour in wheat (Triticum aestivum L.) seeds. J. Pharmac. Phytochem., 6, 932-935 (2017).

Singh, S., Y.P. Yadav, H.P. Yadav, D. Vart and N. Yadav: Morphological characterization of pearl millet hybrids [Pennisetum glaucum (L.) Br.] and their parents. Afr. J. Agric. Res., 11, 371-378 (2016).

Stanton, M.L.: Seed variation in wild radish: Effect of seed size on components of seedling and adult fitness. Ecol., 65, 1105-1112 (1984). 
Sud, S., N.S. Bains and G.S. Nanda: Genetic relationships among wheat genotypes, as revealed by microsatellite markers and pedigree analysis. J. Appl. Genet., 46, 375-379 (2005).

Tanksley, S.D. and S.R. McCouch: Seed banks and molecular maps: Unlocking genetic potential from the wild. Sci., 277, 1063-1066 (1997).

Teare, I.D., J.W. Sij, R.P. Waldren and S.M. Goltz: Comparative data on the rate of photosynthesis, respiration and transpiration of different organs in awned and awnless isogenic lines of wheat. Can. J. PI. Sci., 52, 965-971 (1972).

Tomar, R.S.S., S. Tiwari, Vinod, B.K. Naik, S. Chand and R. Deshmukh: Molecular and morpho-agronomical characterization of root architecture at seedling and reproductive stages for drought tolerance in wheat. PloS ONE, 11, e0156528 (2016).

Venske, E., R. Schreinert dos Santos, C. Busanello, P. Gustafson and A. Costa de Oliveira: Bread wheat: A role model for plant domestication and breeding. Hereditas, 156, 16 (2019).

Wang, L., H. Ge, C. Hao, Y. Dong and X. Zhang: Identifying loci influencing 1,000-kernel weight in wheat by microsatellite screening for evidence of selection during breeding. PIOS ONE, 7, 29432 (2012).

Wasim, M., V.S. Mor, V. Singh, T. Fazily and Hemender: Morphological quantitative characterization of wheat (Triticum aestivum L.) genotypes under normal and late sown conditions. Int. J. Adv. Agric. Sci. Technol., 7, 1-8 (2020).

Wen, D., H. Hou, A. Meng, J. Meng, L. Xie and C. Zhang: Rapid evaluation of seed vigour by absolute content of protein in seed within the same crop. Sci. Rep., 8, 55-69 (2018).

Wulff, R. D.: Seed size variation in Desmodium paniculatum. I. Factors affecting seed size. J. Ecol., 74, 87-97 (1986).

Xia, X., L.L. Luan, G. Qin, L.F. Yu, Z.W. Wang, W.C. Dong, Y. Song, Y. Qiao, X.S. Zhang, Y.L. Sang and L. Yang: Genome-wide analysis of SSR and ILP markers in tress: diversity profiling, alternate distribution and applications in duplication. Sci. Rep., 7, 17902 (2017).

Xie, Q., S. Myes and D.L. Sparkes: Optimizing tiller production and survival for grain yield improvement in a bread wheat $\times$ spelt mapping population. Ann. Bot., 117, 51-66 (2016).

Yanping, Y., G. Rongqui, S. Quingquan and L. Shengfu: Vigour of Welsh onion seeds in relation to storage temperature and seed moisture content. Seed. Sci. Technol., 28, 817-823 (2000).

Zi, Y., J. Ding, J. Song, G. Humphreys, Y. Peng, C. Li, X. Zhu and W. Guo: Grain yield, starch content and activities of key enzymes of waxy and non-waxy wheat (Triticum aestivum L.). Sci. Rep., 8, 45-48 (2018). 